\title{
Non-Monetary Poverty and Deprivation: \\ A Capability Approach
}

\section{Paul Anand, Open University, Oxford University and CPNSS London School of Economics}

\author{
Sam Jones, University of Copenhagen and UN WIDER
}

Matthew Donoghue, Oxford University

Julien Teitler, Columbia University

\begin{abstract}
Summary
Given the continuing interest in multi-dimensional approaches to poverty, the paper considers ways in which Senian capability indicators can be used to assess and understand poverty and deprivation. More specifically, we develop novel capability data on 29 dimensions for adults from the US, UK and Italy to explore three core research questions. Firstly, we show that when poverty is seen as capability deprivation, different individuals are identified as poor compared with approaches based on low income or subjective wellbeing. However, we also observe that what the poor report being able to do or otherwise is, nonetheless, relatively robust to the use of these three different approaches. Secondly, we employ latent class analysis to identify poverty and deprivation profiles for groups within society and suggest that such profiles help to identify groups who are deprived with respect to some but not all areas of life. Thirdly, and finally, we examine the association between individual capability deprivation and local area deprivation in the UK. We find that individual capabilities are associated with local area deprivation in some cases but that the connections vary significantly depending on the dimension under consideration. We discuss the results and conclude by suggesting that capability indicators can provide insights into poverty which do emerge from a more traditional approach focussing on income alone.
\end{abstract}

Acknowledgements

We are grateful to colleagues, at a number of seminars, for comments on aspects of the analysis, as well as the Leverhulme Trust for funding the data used (Award Reference F00269AB) in this study. Particular thanks go to Robert Walker, Fran Bennet and Larry Roope for their comments and contributions to earlier drafts and research, on which the paper is based, as well as seminar participants at the World Bank, the 2016 HDCA conference in Tokyo and members of the poverty group in the Department of Social Policy and Intervention in Oxford. Additional funding, from the Oxford Foundation for Knowledge Exchange for data analysis is also acknowledged. 


\section{Non-Monetary Poverty and Deprivation: A Capability Approach}

\section{Introduction}

In recent years, there has been considerable policy and research interest in analyses of poverty and deprivation that go beyond the traditional resourcist approach. To a significant degree this has been motivated by Sen's $(1985,1999)$ proposal that what a person is able to do is an important aspect of their quality of life and the related view that poverty and deprivation can be seen as states in which capabilities are insufficient. This approach, developed subsequently with political philosopher Martha Nussbaum (e.g., Nussbaum and Sen, (1993)), was founded on three relations key to understanding a person's quality of life. In his original formulation, Sen held that an individual's activities and states depend on resources (e.g., income) and an individual's ability to convert resources into activities and states. Secondly, he suggested that subjective experience depends on the activities and states in which a person is involved. And last, he argued that the assessment of a person's quality of life needs also to allow for opportunities to do things of value. It is these latter positive freedoms or capabilities in Sen's terminology that welfare policies in liberal mixed economies often target and as a result, the rich theoretical structure of the capability approach (CA) adds considerably to the concepts available for poverty and social policy analysis.

Following, work operationalising CA using quantitative primary data, Anand et al (2005, 2009, 2011), Burchardt and Vizard (2011), Coast et al (2008) and Trani et al (2010), this paper contributes to the literature by developing additional direct capability indicators and showing how such data can add to the understanding of poverty and deprivation. This is in contrast to some of the empirical CA projects which employed secondary data - see for instance Qizilbash and Clark (2005), Klasen (2000), Wagle (2008) and Alkire et al (2015). While the use of secondary data is entirely understandable, it is widely recognised that many existing datasets and household surveys often capture only a small part of a person's capability set and/or do indirectly by assessing functionings, Kanbur (2016). For example, the EU SILC now asks whether a person engages in socialising activities and if not whether the absence is due to affordability or preference. Indeed, implementation of the Senian approach has been viewed as depending on the production of such opportunity and constraint data and this paper contributes by considering how new capability data for the US, UK and Italy can be used to enhance the understanding of poverty.

As a result, the paper offers four predominantly methodological innovations. First, it provides one of the first primary datasets of capabilities in three high-income countries for use in poverty and deprivation research based on explicit capability indicators (as opposed to functioning proxies for capabilities drawn from secondary data). Second it uses these data to show that who is poor varies significantly depending on the definition used for identification. Nonetheless, the multi-dimensional patterns of deprivation are reasonable robust to the concept of poverty used (and avoid self-identification as being in poverty, which some have argued against - e.g. Shildrick and MacDonald (2013)). More specifically, we demonstrate that those who are income poor, are not always the same as those who are capability poor, and those who are poor in terms of subjective wellbeing may be different again. Third, it argues for the use of poverty profiles as a way of understanding the sources and nature of multi-dimensional poverty and deprivation. Ravallion (2011) has for example argued against 'mash-up' aggregations of multidimensional poverty indicators and the paper therefore use latent class to identify multidimensional patterns of deprivation. With this approach we find three types of deprivation: those with low capabilities all round, those with low capabilities with respect to work, and those with low capabilities with respect to home. Finally, the paper shows that CA can be used to show that structural factors can predict low individual capabilities, contra concerns about its 
inability to engage with structural factors Dean (2009), and that the relations vary significantly depending on the aspect of poverty under consideration. ${ }^{1}$

As such we hope to make a primarily methodological contribution to the agenda of developing direct non-monetary poverty indicators increasingly accepted by international and national bodies, World Bank (2017), Rippin (2016) and by researchers seeking to bring in other dimensions such as health, Neckerman et al (2016) or concepts based on several dimensions, such as inclusion, Kunzel (2012), Lin et al (2013) or work-life balance, Lewis and Guillari (2005). The rest of the paper is structured as follows. Section 2 covers the theoretical framework and methodology used to analyse the data. Section 3 introduces the primary data on capabilities and other variables. Sections 4 to 5 present empirical results relating to classification, multidimensional poverty profiles and connections between local area deprivation and individual capabilities respectively. The final section offers some further discussion and concluding remarks.

\section{A Theoretical Framework for Poverty and Deprivation Analysis}

Using Sen's theoretical framework, it may be argued that poverty amounts to low quality of life in terms of various aspects: activities, experience and capabilities. There are affinities also with Marshall's (1950) earlier proposal that nation states go beyond basic economic security by recognising their duties to involve citizens in the full 'social heritage' of a country. Furthermore, and despite his criticism of the Senian approach, Townsend's call for a refocussing away from income poverty to being able to take part in society has a strong capabilitarian feel to it. Within a European policy context, Atkinson et al (2002) provided one of the first sustained explorations of how multi-dimensional indicators might reflect exclusion, (and subsequently multi-dimensional poverty has been explored particularly by Nolan and Wheelan (2010) and Wheelan et al (2014)). In any case, these aspects of life quality are connected and depend on the resources (non-financial as well as monetary) to which a person has access and their ability to convert those resources into the activities and states. Figure 1 offers a visual summary of core concepts and relations.

\section{*** INSERT FIGURE 1 ABOUT HERE ***}

At the start sit material resources, often measured in terms of financial income and assets. Income matters, in this framework though not as a proxy for well-being or even as a measure of consumption possibilities, but rather as an input into the production of activities, states and experiences. Income measures aside, most of the variables in this framework are inherently multivariate in nature; in addition, theory emphasises that individuals differ in their abilities to make use of resources. Poverty measurement standardly controls for household composition, but CA emphasises additional factors (referred to as conversion factors), from personal traits to legal entitlements and social norms that impact the ability to make good use of resources. Deficits in any of these elements are relevant to understanding or addressing poverty.

In principle therefore, and with the right datasets, the approach can sustain not just a multidimensional measure of poverty but also track the drivers and consequences of low levels of capability. There are various ways in which the framework in Figure 1 could be used to support poverty research and in this paper, we focus particularly on the use of direct and explicit survey measures of capabilities as they are the most distinctive part of Sen's set-up and are essential

\footnotetext{
${ }^{1}$ Direct person specific capability indicators reflect both individual and structural factors and so can help to avoid the difficulty identified by Dagdeviren et al (2016) that follows from using traits such as resilience without reference to information about the context in which such traits might be protective. For reasons of space, as well as data availability, we do not dwell on direct comparisons between countries though point to analyses based on the data (eg Anand et al (2016)) which do identify some country/cultural drivers of capabilities.
} 
for quality of life achievements. Some capability variables already exist in household surveys and we produce data here that expands the variables covered in line both with an academic account produced by the political theorist, Martha Nussbaum (2000) but also with modifications informed by a national level consultation by the Office of National Statistics, ONS (2012) as well the research literatures on health and social indicators. In the next section, we describe the data developed in line with Figure 1.

\section{Capability and other data for Italy, UK and USA}

In this section we examine how the poor can be identified and their associated characteristics. To do so, we use our own 2011 Oxwell survey of working adults, which was collected in three countries (Italy, USA and UK). As the team were substantially based in Oxford, it was felt appropriate to collect data for the UK and two other countries that might offer interesting contrasts. The US shares some market plus regulation features of its economic system with the UK though has different approaches to welfare and so is an interesting choice. Italy offers a contrast with respect to its legal system (civil) as well its welfare regime (classified as corporatist conservative). The Oxwell survey was designed, primarily, to collect data on capabilities, activity involvement, subjective well-being, material resources (household and personal income) and social resources - that is, data relating to all the elements of the theory summarized in Figure 1. The survey was administered by YOUGOV, who employ panels constructed to be roughly representative of the national population. The necessity of their approach is driven, in part, by the fact that electoral registers in the UK are no longer be regarded as definitive sampling frames, since voters are allowed to opt-out of the public access versions.

Descriptive statistics for our data can be found in Table $\mathrm{O} 1^{2}$. Panel (a) reports basic individual characteristics, including mean after-tax incomes and the average of the subjective well-being (SWB) score; which is based on a Likert scale, ranging from 0 to 10 , where higher values indicate a more positive evaluation. Panel (b) reports the proportion of the sample, in each country, residing in different locations (e.g., rural vs. inner city). Note that the survey was intended to be roughly representative with respect to the age, gender and social class of the working age population (aged 20-62) in each country. This is supported by comparing the main survey aggregates with official national estimates.

Panels (c) through $(\mathrm{g})$ report information on twenty-nine capability indicators, across five broad domains: home, work, community, the environment in which a person lives and access to services. (These groupings were designed to provide a high level way of checking coverage all categories are clearly important in several ways so the absence of indicators in any one category can be taken as evidence of a significant omission.) For each of these capabilities, respondents were asked questions of the form 'I am able to ...' and all responses were reported, again, on a scale ranging from 0 (strongly disagree) to 10 (strongly agree).

When a large number of scales are used, as a basis for analysis, two concerns may arise. The first is that the individual scales are not well-behaved, meaning that they cannot be treated as if they are continuous (numbers rather than categories). To look at this, Appendix Table A1 investigates the shape of the distributions of the capability indicators. By counting modes (averages) and following the general advice of Normal (2010), we are satisfied that we can treat these indicators in a parametric fashion.

A second concern is that multiple indicators may be overlapping and, therefore, contain largely redundant information. To test this, we run two factor analyses and consider the uniqueness of each indicator, after extracting common factors. These results are shown under column (II) of the table. The first sub-column, 'Overall', extracts a single common factor from the 29

2 Online tables have numbers prefixed $\mathrm{O}$. 
indicators. While this removes some information, the average uniqueness (theoretically ranging from 0 to 1) remains substantial at $65 \%$. The second column repeats the same analysis, but does so for each group (panel) of capabilities separately; e.g., one factor for home life, one for work and so on. As expected, residual uniqueness falls, but nonetheless remains greater than $50 \%$ on average, and is always larger than around $30 \%$. This suggests that while there are some commonalities across the indicators (as expected), there is no reason to either drop individual indicators or to collapse them prior to further analysis.

\section{Results: who is poor and in what ways?}

We begin our overview of the main empirical results by looking at the classifications of those who are poor. To do so, we construct three separate measures of poverty (deprived). These are income poverty, SWB poverty and capability poverty. The first two metrics are derived by taking as income and SWB poor those who are in the lowest fifth of the respective distributions (see panel (a) of Table 1). To classify an individual as capability poor, we apply an AlkireFoster procedure (Alkire et al, 2015) to the assessment of multidimensional deprivation. Concretely, in each country, we apply a poverty threshold for each indicator at the $40^{\text {th }}$ percentile of its distribution. ${ }^{3}$ We then count the number of dimensions, in which each individual is deprived, and conclude they are capability poor if they are deprived on more than half of all dimensions (for which they have non-missing data). Again, this procedure identifies around one fifth of respondents as poor.

Table 1 considers the degree of overlap between these measures of poverty; i.e., do they consistently classify the same people as poor? The broad answer is no. Panels (a) through (c) of the table report two-way cross-tabulations, where the cells give the proportion of respondents in each combination of the two binary variables shown. It is noteworthy that across the three tabulations, there is an overlap, or agreement, of no more than $50 \%$ in terms of who is classified as poor. ${ }^{4}$ This is calculated as the proportion of respondents, classified as poor by both of the two measures, divided by the mean share of poor on any one measure. Moreover, the degree of concordance is lowest, when income poverty is included; e.g., only $5.6 \%$ of respondents are both income and capability poor, compared to an average of $22 \%$ across the two measures, implying they agree on who is poor less than half of the time. The simple correlation coefficients, shown in panel (d), confirm this conclusion. These findings are in line with those of Laderchi et al. (2003) who also found that different people are identified as poor, when capability indicators and other measures are used.

Table 1: Relationships between metrics of poverty

(a) Income vs capability poverty

\begin{tabular}{lcrr|r} 
& & \multicolumn{3}{c}{ Capability poor } \\
\cline { 3 - 5 } & & \multicolumn{3}{c}{} \\
& No & \multicolumn{1}{c}{ Yes } & \multicolumn{1}{c}{ Total } \\
\hline \multirow{2}{*}{ Income poor } & No & 62.4 & 16.3 & 78.7 \\
& Yes & 15.7 & 5.6 & 21.3 \\
\hline & Total & 78.1 & 21.9 & 100.0
\end{tabular}

(c) Capability vs SWB poverty (b) Income vs SWB poverty

\begin{tabular}{ccrr|r} 
& & \multicolumn{3}{c}{ SWB poor } \\
\cline { 3 - 5 } & & \multicolumn{3}{c}{} \\
& No & \multicolumn{1}{c}{ Yes } & \multicolumn{1}{c}{ Total } \\
\hline Income & No & 63.6 & 15.1 & 78.7 \\
poor & Yes & 14.4 & 6.9 & 21.3 \\
\hline & Total & 78.0 & 22.0 & 100.0
\end{tabular}

(d) Correlation matrix:

\footnotetext{
3 It should be noted that other thresholds could be used and that this would give rise to different totals in poverty. However, given the small number of categories in our underlying data, there is little scope to explore the consequences of different thresholds for these data.

${ }^{4}$ In the Appendix, we provide two alternative cross-tabulations based on different overall cut-offs for classifying who is capability poor. These do not alter the overall conclusions.
} 


\begin{tabular}{|c|c|c|c|c|c|c|c|c|}
\hline & & No & Yes & Total & & SWB & Capability & Income \\
\hline \multirow{3}{*}{$\begin{array}{c}\text { Capability } \\
\text { poor }\end{array}$} & No & 67.2 & 10.8 & 78.1 & SWB & 1 & & \\
\hline & Yes & 10.8 & 11.2 & 22.0 & Capability & $0.3709^{*}$ & 1 & \\
\hline & Total & 78.0 & 22.0 & 100.0 & Income & $0.1288^{*}$ & $0.0557^{*}$ & 1 \\
\hline
\end{tabular}

Notes: Panels (a) to (c) are two-way cross-tabulations, in which cells are the proportion of responses in each combination (pooled sample); panel (d) reports correlation coefficients. For example in Table 1 (a), the proportion of the sample with the same poverty classification following both the income and capability deprivation definitions is $68.0 \%(64.2+5.6 \%)$. Therefore $32 \%$ of the population change their poverty classification depending on the definition used.

One way to understand poverty classification, is to consider the distribution of the poor by their socio-economic status. Thus, we examine gradients that describe the proportions of people, who are classified as poor, by employment status (working individuals only), sex, age and neighbourhood type (location). The results pooled for three countries, reported in Table O2, suggest that subjective well-being defines a proportion of professionals as being in the lowest quintile and that the poverty gradient between status groups is sharpest when poverty is measured in terms of low income, but flatter for the other measures. So, for example, while less than $10 \%$ of our sample show up as income poor, nearly $20 \%$ are capability poor. Some gender disparities also merit attention. The proportions of professional women who are income or capability poor are rather similar, whereas the proportion is much lower for men, when being poor is measured in terms of income. Furthermore, a relatively high proportion of women, in non-manual work, are classified as poor in subjective well-being (SWB) terms.

Poverty and deprivation gradients, by age and residential location, are slightly more complicated. For example, the lowest proportions of those classified as poor, by income, are generally found in the suburbs, whereas the counterpart location varies in capability terms, from towns, or the under 30s, through rural areas, to the suburbs, for those over 50. Subjective wellbeing gradients are less steep: for those under 30 and over 50, and rural areas have the highest proportions of those classified as poor. Although it might be natural to think of the inner city as the location where poverty is centred, rural areas, in some high-income countries, also contain higher proportions of people whose experience of life quality is relatively low. A variety of contextual factors, particularly the extent of public transport, access to low price shops and labour market characteristics can combine to make rural living an expensive and isolating experience - see for instance Cotter's (2002) discussion of opportunity structures.

\section{Further results: ranking and latent class modelling}

To examine these data in multivariate terms, we now consider rankings, by the poor, of their capabilities and the results of latent class modelling. The rankings are shown in Table 2 and are calculated by taking the average scores, in each of the capability measures, for those classified as poor (by some measure) and then ordering these from highest to lowest. The results show that, no matter which of the three conceptions of poverty or deprivation is used, the capabilities relating to politics, access to shops and garbage clearance appear, roughly, in the top four (both for females and males, not shown). Looking at those classified as income poor, the bottom three capabilities are; having opportunities to progress in work, local participation in the community and the work-life balance. But these are also common across the measures. Indeed, the correlation between the rankings is more than $90 \%$ in all three cases, rising to $98 \%$ for the rankings given by the SWB and the capability poor; in other words, there is almost complete agreement in these orderings. 
Another way to look at the multivariate nature of poverty and deprivation is to examine whether people can be meaningfully clustered, with respect to the various aspects of well-being. To examine this question, we use latent class modelling, which automatically classifies individuals into one of a given number of clusters or classes, based on their scores across the capability measures. Table $\mathrm{O} 3$ reports the statistical results for analyses, using different numbers of classes. In all three countries, we find evidence that around 10 groups (specifically, 9 or 11) minimise the BIC criterion, which is a commonly used as a measure of fit, between the data and model (number of classes).

Given the similarities across the countries and for reasons of space, we explore the latent class results for the UK. Table 3 reports the mean values, of the underlying capability metrics, within each latent class (given in columns). To assist interpretation, the table reports these average metrics in standardised form; i.e., in standard deviation units around the mean. Table $6 \mathrm{~b}$ reports additional summary statistics for each latent class (in rows), including the share, in each class classified as poor. Taking the two tables together, a number of findings merit

Table 2: Means and rankings of capabilities by individuals classified as poor by type

\begin{tabular}{|c|c|c|c|c|c|c|c|c|}
\hline & \multirow[t]{2}{*}{ Capability } & \multicolumn{2}{|c|}{ Income poor } & \multicolumn{2}{|c|}{ SWB poor } & \multicolumn{2}{|c|}{ Capability poor } & \multirow{2}{*}{$\begin{array}{c}\text { Equal. } \\
\text { test } \\
\text { (Prob.) }\end{array}$} \\
\hline & & Mean & Rank & Mean & Rank & Mean & Rank & \\
\hline \multirow[t]{7}{*}{ Home } & Share tasks fairly & 6.02 & 22 & 4.92 & 17 & 4.53 & 15 & $(0.00)$ \\
\hline & Socialise with family & 6.57 & 12 & 5.03 & 16 & 4.56 & 14 & $(0.00)$ \\
\hline & Make ends meet & 5.47 & 26 & 4.08 & 25 & 4.13 & 24 & $(0.00)$ \\
\hline & Work-life balance & 5.45 & 27 & 3.80 & 27 & 3.86 & 27 & $(0.00)$ \\
\hline & Suitable home & 6.20 & 18 & 4.73 & 20 & 4.25 & 20 & $(0.00)$ \\
\hline & Personal relations & 5.99 & 23 & 3.86 & 26 & 3.92 & 26 & $(0.00)$ \\
\hline & Feel loved and valued & 6.29 & 16 & 4.15 & 24 & 4.14 & 23 & $(0.00)$ \\
\hline \multirow[t]{6}{*}{ Work } & Find work & 5.57 & 24 & 4.36 & 23 & 4.18 & 21 & $(0.00)$ \\
\hline & Use talents & 6.61 & 11 & 4.85 & 18 & 4.49 & 16 & $(0.00)$ \\
\hline & Good manager & 6.09 & 20 & 4.73 & 19 & 4.29 & 19 & $(0.00)$ \\
\hline & Treated as equal & 6.66 & 10 & 5.28 & 14 & 4.62 & 13 & $(0.00)$ \\
\hline & Opportunities to progress & 5.38 & 28 & 3.14 & 29 & 3.19 & 29 & $(0.00)$ \\
\hline & Socialise with colleagues & 6.13 & 19 & 4.46 & 22 & 4.17 & 22 & $(0.00)$ \\
\hline \multirow[t]{4}{*}{ Community } & Local participation & 5.12 & 29 & 3.71 & 28 & 3.44 & 28 & $(0.00)$ \\
\hline & No discrimination & 6.95 & 6 & 5.87 & 9 & 4.89 & 9 & $(0.00)$ \\
\hline & Religious freedom & 7.58 & 1 & 6.91 & 1 & 5.75 & 1 & $(0.00)$ \\
\hline & Political freedom & 7.16 & 4 & 6.36 & 6 & 5.28 & 6 & $(0.00)$ \\
\hline \multirow[t]{5}{*}{ Environment } & Walk at night & 6.44 & 15 & 5.81 & 11 & 4.79 & 10 & $(0.00)$ \\
\hline & Able to visit parks & 6.87 & 8 & 6.19 & 7 & 5.06 & 8 & $(0.00)$ \\
\hline & Low pollution & 5.47 & 25 & 4.59 & 21 & 4.06 & 25 & $(0.00)$ \\
\hline & Can keep pet & 6.88 & 7 & 6.37 & 5 & 5.38 & 5 & $(0.00)$ \\
\hline & Can get to places & 6.51 & 13 & 5.63 & 12 & 4.79 & 11 & $(0.00)$ \\
\hline \multirow[t]{5}{*}{ Services } & Financial services & 7.04 & 5 & 6.49 & 4 & 5.56 & 3 & $(0.00)$ \\
\hline & Garbage cleared & 7.19 & 2 & 6.52 & 3 & 5.44 & 4 & $(0.00)$ \\
\hline & Home problems fixed & 6.25 & 17 & 5.45 & 13 & 4.43 & 17 & $(0.00)$ \\
\hline & Doctor / nurse & 6.73 & 9 & 6.18 & 8 & 5.13 & 7 & $(0.00)$ \\
\hline & Police & 6.50 & 14 & 5.81 & 10 & 4.75 & 12 & $(0.00)$ \\
\hline
\end{tabular}




\begin{tabular}{lccccccc} 
Legal support & 6.03 & 21 & 5.25 & 15 & 4.32 & 18 & $(0.00)$ \\
Range of shops & 7.16 & 3 & 6.53 & 2 & 5.56 & 2 & $(0.00)$ \\
\hline
\end{tabular}

Notes: each cell reports the average capability score for individuals classed as either income, SWB or capability poor; the final column tests whether the capability measure (in each row) is correlated in the same way to each of the three poverty measures, based on separate bivariate regressions followed by tests of coefficient equality.

comment. Firstly, and as expected, there are groups with both mostly low and mostly high capabilities. The former comprise about $5 \%$ of the sample and the latter around $12 \%$. Looking at characteristics of the first latent class (mostly low capabilities), we note that while they have a heavy weighting towards the lowest income group, only $27 \%$ are classified as income poor. Nonetheless, they display the lowest subjective well-being, are generally young, show poor health (a subjective measure scaled from zero to one), and are more likely to be of non-white ethnicity. This result is rather similar to that found by Anand et al. (2009), who also find that the worst-off group, within the UK, was relatively young and likely to have significant health problems. 


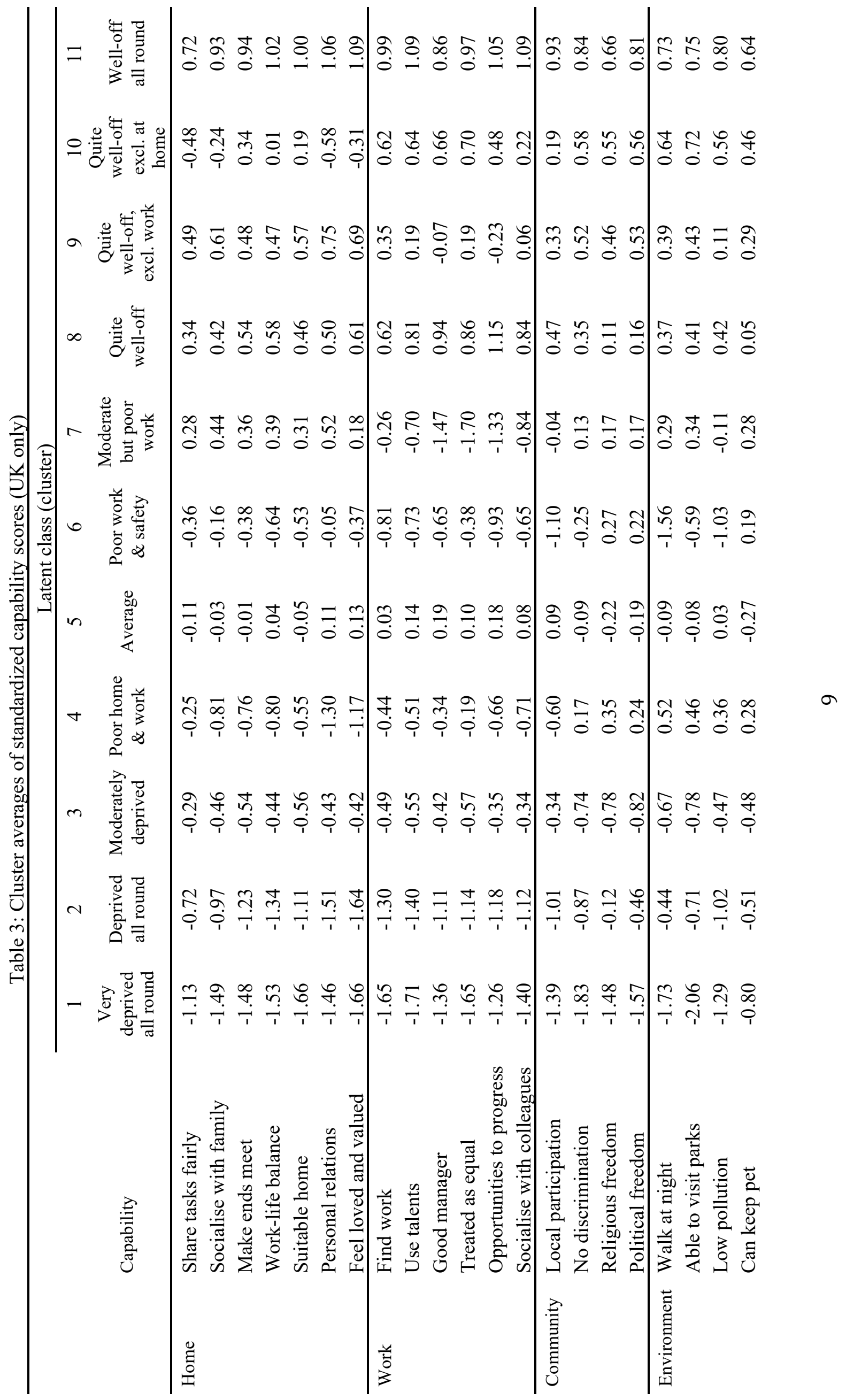




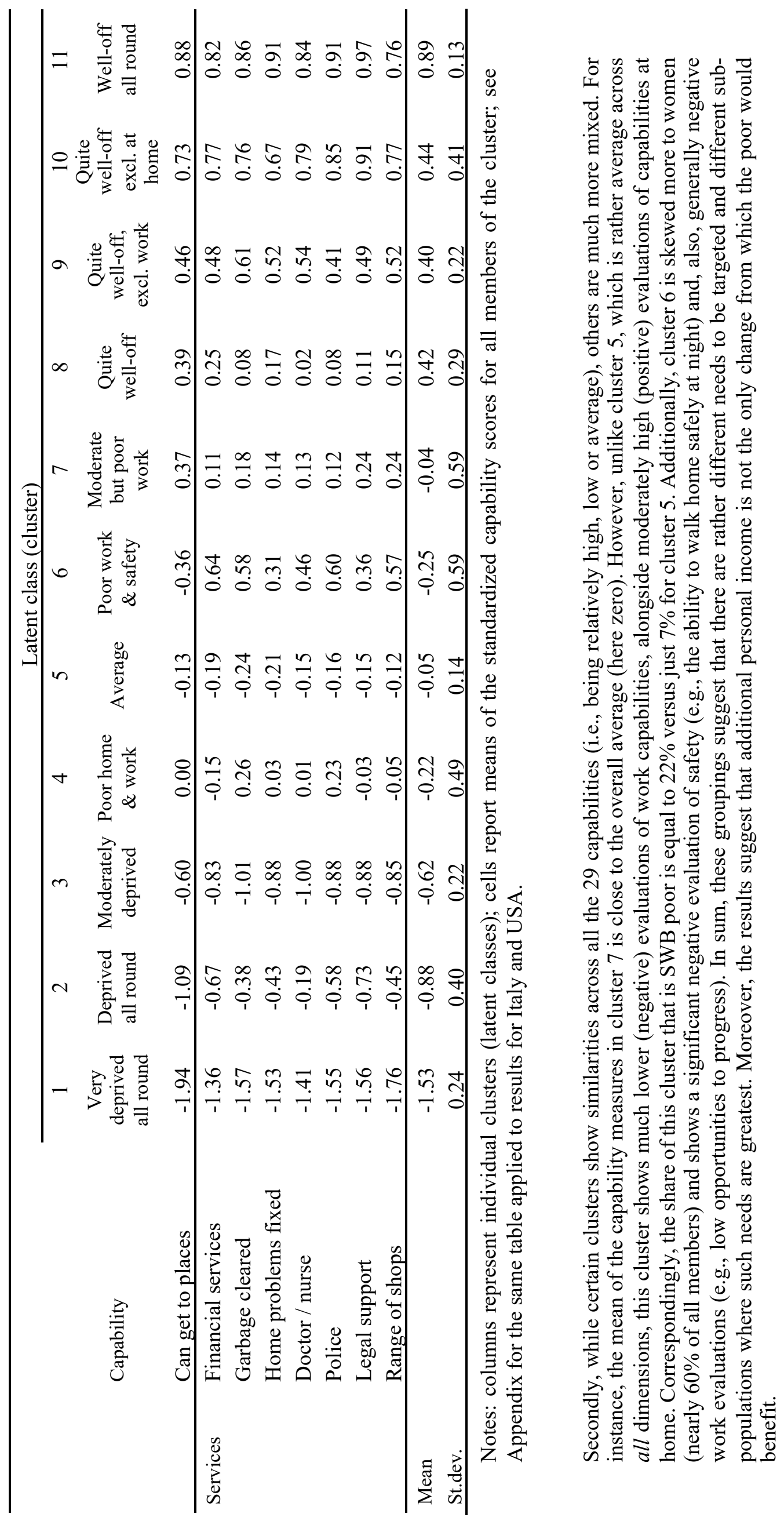




\section{How are individual capability indicators related to local neighbourhood deprivation?}

\section{Additional UK data on deprivation}

In this section we connect the previous metrics, of individual well-being, to the broader measures of local area deprivation, which apply to specific geographic locations. To do this we draw on deprivation indicators which exist only for the UK and so focus the final analysis on that country. Specifically, we draw on the components of the UK government's Index of Multiple Deprivation (IMD), which was designed to capture local deprivation with respect to the following main dimensions: income, employment, health, education, access to services, crime and environment (developed for government by McLennen et al (2011). ${ }^{5}$ At its most micro level, the IMD contains data on ${ }^{6} \mathrm{LSOAs}$, which have a mean population of around 1,600 individuals. The indices are also available at the more aggregated level of Upper Tier Local Authority (UTLA). UTLAs are composed, on average, of around 210 LSOAs, or 335,000 individuals. The UTLA-level IMD are derived from the LSOA-level IMD as population weighted averages. The analysis, undertaken here, uses observations for 585 working-age adults, where we can match the capability data and that of the IMD. Specifically, we were able to ascertain the LSOA where the person lives, in 285 cases (using postcode data they were prepared to supply), and the UTLAs for the remaining 300 individuals.

Table O5 describes the summary statistics for the merged dataset. Panel (a) reports basic individual characteristics. Compared to the Oxwell survey, which we noted was broadly representative of the UK population, we find clear continuities; e.g., in the merged local area dataset we find $61 \%$ of individuals have a partner (versus $60 \%$ in the Oxwell survey) and $93 \%$ are of white ethnicity (versus 95\%). Panel (b) of Table O5 reports the aggregate IMD score and panel (c) reports the individual underlying components. Of interest, here is that the mean of the present data falls squarely at the midpoint of the full local area data (i.e., nationwide). This is shown by the fact that the mean fractional rank (percentile), of the component scores, is around 50 and the minimum and maximum range from close to zero to around 100. Consequently, despite the selective nature of the merged dataset, we have no reason to believe that it is significantly unrepresentative of the broader country.

\section{Results}

Our analytical interest, here, concerns the connections between local area deprivation and poverty/deprivation, at the individual level. In particular, we are interested in knowing the extent to which the former might be able to predict the latter; e.g., the presence of clear connections would point to the relevance of policies targeted at localities rather than just individuals (or vice versa). To begin, we compare average capability scores in areas of high and low local deprivation, as defined by English IMD score thresholds. These results are reported in Table 4. Overall, they show that environment-related capabilities are uniformly lower, in more deprived areas. In fact, all individual capability indicators are lower, on average, in deprived areas; however, the strength of association, as indicated by t-tests, is far from uniform. Home and work capabilities show a distinctly mixed pattern, in which roughly only half the indicators are statistically lower in deprived areas. This suggests that capabilities, which are more personal/social in nature, are generally less correlated to broader measures of local area deprivation. That said, being able to make ends meet and having a job that allows a person

\footnotetext{
5 For further details and data see: https://www.gov.uk/government/statistics/english-indices-ofdeprivation-2010.

${ }^{6}$ LSAO is the Lower Layer Super Output Area, a geographical area, designed to improve local area statistics reporting in England and Wales. The ONS data are not updated annually and the closest available data to our own were released in 2012 .
} 
to use their talents and skills are significantly related to neighbourhood deprivation. This suggests that deprived areas, in the UK, are composed of households that have difficulties in 
Table 4: Mean capabilities in most and least deprived areas

\begin{tabular}{|c|c|c|c|c|c|c|c|}
\hline & \multicolumn{3}{|c|}{ Most deprived } & \multicolumn{3}{|c|}{ Least deprived } & \multirow[b]{3}{*}{ t-test } \\
\hline & \multicolumn{3}{|c|}{$(\mathrm{IMD}>26.91)$} & \multicolumn{3}{|c|}{$(\mathrm{IMD}<11.45)$} & \\
\hline & $\mathrm{n}$ & Mean & S.E. & $\mathrm{n}$ & Mean & S.E. & \\
\hline \multicolumn{8}{|l|}{ (a) Home life } \\
\hline Share tasks fairly & 141 & 6.09 & 0.25 & 126 & 6.51 & 0.26 & -1.177 \\
\hline Socialise with family & 141 & 6.43 & 0.24 & 126 & 6.71 & 0.22 & -0.882 \\
\hline Make ends meet & 141 & 6.01 & 0.26 & 126 & 6.82 & 0.24 & $-2.296^{* *}$ \\
\hline Work-life balance & 141 & 5.45 & 0.27 & 126 & 6.22 & 0.23 & $-2.174 * *$ \\
\hline Suitable home & 141 & 6.27 & 0.24 & 126 & 6.99 & 0.24 & $-2.153 * *$ \\
\hline Personal relations & 141 & 5.97 & 0.25 & 126 & 6.15 & 0.25 & -0.533 \\
\hline Feel loved and valued & 141 & 5.94 & 0.25 & 126 & 6.26 & 0.24 & -0.932 \\
\hline Sub-group mean & 141 & 6.02 & 0.22 & 126 & 6.52 & 0.21 & -1.198 \\
\hline \multicolumn{8}{|l|}{ (b) Working life } \\
\hline Find work & 103 & 6.16 & 0.27 & 104 & 7.07 & 0.24 & $-2.534 * *$ \\
\hline Use talents & 103 & 6.25 & 0.24 & 104 & 7.41 & 0.21 & $-3.653 * * *$ \\
\hline Good manager & 103 & 6.19 & 0.29 & 104 & 6.82 & 0.24 & -1.642 \\
\hline Treated as equal & 103 & 6.68 & 0.29 & 104 & 7.68 & 0.21 & $-2.799 * * *$ \\
\hline Opportunities to progress & 103 & 4.76 & 0.30 & 104 & 5.23 & 0.29 & -1.14 \\
\hline Socialise with colleagues & 103 & 5.70 & 0.27 & 104 & 5.72 & 0.25 & -0.059 \\
\hline Sub-group mean & 103 & 5.96 & 0.21 & 104 & 6.66 & 0.19 & $-2.074 * *$ \\
\hline \multicolumn{8}{|l|}{ (c) Community } \\
\hline Local participation & 141 & 4.75 & 0.24 & 126 & 5.37 & 0.23 & $-1.835^{*}$ \\
\hline No discrimination & 141 & 6.75 & 0.22 & 126 & 7.45 & 0.20 & $-2.349 * *$ \\
\hline Religious freedom & 141 & 7.39 & 0.23 & 126 & 7.89 & 0.19 & $-1.699 *$ \\
\hline Political freedom & 141 & 7.07 & 0.20 & 126 & 7.52 & 0.19 & -1.597 \\
\hline Sub-group mean & 141 & 6.49 & 0.13 & 126 & 7.06 & 0.11 & $-2.802 * * *$ \\
\hline \multicolumn{8}{|l|}{ (d) Local environment } \\
\hline Walk at night & 141 & 5.83 & 0.23 & 126 & 7.37 & 0.19 & $-5.112 * * *$ \\
\hline Able to visit parks & 141 & 6.87 & 0.23 & 126 & 7.89 & 0.185 & $-3.433 * * *$ \\
\hline Low pollution & 141 & 4.96 & 0.25 & 126 & 6.28 & 0.226 & $-3.886^{* * *}$ \\
\hline Can keep pet & 141 & 6.57 & 0.28 & 126 & 7.40 & 0.273 & $-2.120 * *$ \\
\hline Can get to places & 141 & 6.88 & 0.24 & 126 & 8.02 & 0.172 & $-3.890 * * *$ \\
\hline Sub-group mean & 141 & 6.22 & 0.14 & 126 & 2.89 & 0.124 & $-4.039 * * *$ \\
\hline \multicolumn{8}{|l|}{ (e) Access to services } \\
\hline Financial services & 141 & 7.86 & 0.17 & 126 & 8.00 & 0.186 & -0.565 \\
\hline Garbage cleared & 141 & 7.45 & 0.19 & 126 & 8.06 & 0.173 & $-2.373 * *$ \\
\hline Home problems fixed & 141 & 6.33 & 0.23 & 126 & 7.35 & 0.185 & $-3.490 * * *$ \\
\hline Doctor / nurse & 141 & 7.17 & 0.21 & 126 & 7.64 & 0.19 & -1.641 \\
\hline Police & 141 & 6.27 & 0.23 & 126 & 7.19 & 0.207 & $-3.010 * * *$ \\
\hline Legal support & 141 & 6.28 & 0.22 & 126 & 7.06 & 0.221 & $-2.481 * *$ \\
\hline Range of shops & 128 & 7.67 & 0.20 & 121 & 8.18 & 0.174 & $-1.912 *$ \\
\hline Sub-group mean & 128 & 7.00 & 0.19 & 121 & 7.64 & 0.173 & $-2.653 * * *$ \\
\hline
\end{tabular}


Notes: cells report means of reported capabilities above and below the least and most deprived thresholds; t-tests indicate systematic differences between the groups.

Source: author calculations.

managing finances, for whatever reasons, and also have labour markets that are relatively thin in terms of good quality jobs.

Table O6 further explores these results, exploiting the fact that the overall IMD score is based on scores within the subdomains of deprivation. Thus, for each of the capabilities, we estimate a simple regression model (using backward elimination as an exploratory tool), in which the relevant capability depends on aspects of local area deprivation (selecting aspects in a small number of cases to avoid issues of multi-collinearity). These findings indicate that (higher levels of) local deprivation with respect to income, employment and safety are systematically associated with (lower) individual capabilities across a range of domains.

\section{Discussion and Conclusions}

The value of using multi-dimensional perspectives to understand poverty is now widely accepted though it remains open how this is best be done. The approach we have focussed on here involves the use of indicators concerning what a person is able to do in five domains and suggests that capability deprivation: (i) defines different people as poor and (ii) reaches higher up into professional groups, when compared with a financial poverty approach, (iii) has income gradients that vary significantly depending on the aspect of life quality under consideration, (iv) identifies groups partly deprived in the middle of the population and (v) has widely varying degrees of association with local area deprivation. These empirical results show that whilst capabilities depend on resources, what a person is able to do in different areas of life cannot simply be read off from income.

When it comes to measurement and policy, there are at least two reasons for embracing multidimensionality. In the first place, it is useful to have a more detailed picture of material deprivation but in addition, we would like to have an approach that is flexible enough to include social and opportunity aspects of wellbeing. Capability indicators are one, theory-based way of developing broader measures of disadvantage and can be applied to a wide range of topics central to life quality. Debates about absolute versus relative concepts of poverty could apply equally as well to capabilities but in a multi-dimensional deprivation context there are additional questions. The distinction between comprehensive and partial indicators is a case in point. To assess an individual's overall position, a set of indicators needs to include all the dimensions that could contribute to a person being judged to be in a state of poverty. However, for some purposes, related to understanding or advocacy, it might be more appropriate to focus on partial measures dealing particular types of poverty (food and energy poverty are examples). In addition, it is important to distinguish between multi-dimensional profiles which characterise groups or individuals in terms of the multi-variate patterns of deprivation, and the creation of indices which provide a single number of summary. Both profiles and indices have roles to play for while indices are particularly useful for comparison between units or over time, profiles allow for types of partial poverty to be identified.

It is also worth noting that the structure and orientation of Sen's approach when applied to poverty enables a distinction to be made between resource deficits and resource-conversion deficits. Resource deficits may be due to lack of income as in financial poverty, but they could also include lack of social resources such as community and individual social capital the absence of which can make it harder for people to function socially and economically. 
Finally, it may help to review some of the key methodological decisions about our summary index of capabilities as a potential indicator for use a multi-dimensional poverty index. Five core domains have been used as a way of helping to assess the breadth of quality of life issues covered. The five domains were chosen to be comprehensive and relevant to policy in terms of quality of life - and we suggest they are a useful guide for poverty assessment. The 29 capability indicators used here are consistent with these five domains and derive from a survey based on all forty plus sub-items on Nussbaum's (2000) list. However, the current indicators have also been informed by respondent priorities identified through focus group work, Lorgelly et al (2015), national consultation ONS (2011), as well as known policy priorities and model results. It should be recognised that there is no uniquely correct list as this depends on the research question to hand though we believe these indicators also provide a useful starting point for replications in other countries and other subpopulations.

The thresholds used, $\left(40^{\text {th }}\right.$ percentile) were the same for all capabilities as there was no basis on which to weigh them differentially so not indicator specific and the overall cut-off was $50 \%$, meaning that individuals who are deprived on over half of all domains are classified as capability poor. With cardinal data (numerically, rather than rank, meaningful) the implications of using different cut-offs can be further explored and this could be an aid to robustness analysis in some settings. Our primary purpose here has been to use direct capability indicators in a comparative study of poverty assessments and from that perspective any particular indexation may be considered illustrative. In terms of poverty measurement alone, however, we suggest that the capability indicators used here demonstrate the feasibility and argument for using direct capability assessments as supplements to income and also that the particular indicators used could be applied in a range of settings and populations. Although the use of direct capability indicators is limited by their availability in secondary datasets, this provides an opportunity both for primary data research and to influence the designers of household surveys.

To highlight some of our key methodological conclusions and empirical findings:

(i) Comparisons of within country rankings suggests that what people are able to do reflects structural features of the economy and society in which individuals live with a few exceptions relating to the prevailing political economy.

(ii) Multi-dimensional poverty profiles identify patterns of deprivation that go beyond measures of poverty depth or breadth - for example some people seem to be particularly deprived with respect to capabilities related to work or to the home.

(iii) Self-reported capabilities related to environmental factors are, in the UK at least, significantly correlated with external objective deprivation indicators suggesting that household survey methods can be used to provide direct evidence on capabilities for use in modelling poverty.

(iv) Relations between capabilities and income seem to vary significantly which suggests that the latter cannot be used as a simple, uniform proxy for all aspects of poverty and deprivation.

As far as we are aware, this is the first paper on poverty that uses direct, capability indicators in combination with the Alkire-Foster method (counting up dimensions in which a person is deprived) that has recently become popular within the fields of poverty and development. One limitation of the study is that it relies on cross-sectional data and so, future work should examine quality of life dynamics within the framework. That said we believe this paper will help researchers understand some of the ways in which CA, initially conceived as a critique of traditional welfare economics, can, in general, be operationalised directly and quantitatively, thereby delivering on its promise as a tool for social policy analysis, Hick (2012). Maison et al (2014), to take one example, discuss how a welfare state might enhance capabilities and even in policy regimes where income is the focus, it could be that capabilities and constraints outside of work (ie other than educational attainment) are important contributors to deprivation. In addition, the results concerning poverty and deprivation may not only contribute to debates, 
about the options for monitoring multi-dimensional poverty, but are also suggestive of the need for poverty reduction and alleviation policies to be tailored to the socio-economic characteristics of potential policy beneficiaries.

\section{References}

Alkire, S. and Foster, J., Seth, S, Santos M. E., Roche, J. M and Ballon, P. (2015) Multidimensional Poverty Measurement and Analysis, Oxford, Oxford University Press

Anand, P., Hunter, G. and Smith, R., (2005). Capabilities and well-being: evidence based on the Sen-Nussbaum approach to welfare. Social Indicators Research, 74(1), pp.9-55.

Anand, P., Hunter, G., Carter, I., Dowding, K., Guala, F., and Van Hees, M. (2009) 'The development of capability indicators,' Journal of Human Development and Capabilities, 10, pp. 125-152.

Anand, P., Krishnakumar, J. and Tran, N.B. (2011) 'Measuring welfare: Latent variable models for happiness and capabilities in the presence of unobservable heterogeneity'. Journal of Public Economics, 95(3), pp. 205-215.

Atkinson, T, Cantillon B., Marlier E. and Nolan B. (2000) Social Indicators: The EU and Social Inclusion, Oxford, Oxford University Press

Burchardt, T. and Vizard, P. (2011), 'Operationalizing' the Capability Approach as a Basis for Equality and Human Rights Monitoring in Twenty-first-century Britain', Journal of Human Development and Capabilities, 12, pp. 91-119.

Coast, J., Flynn, T.N., Natarajan, L., Sproston, K., Lewis, J., Louviere, J.J. and Peters, T.J., (2008). Valuing the ICECAP capability index for older people. Social science \& medicine, 67(5), pp.874-882.

Cotter, D.A., 2002. Poor people in poor places: Local opportunity structures and household poverty. Rural Sociology, 67(4), pp.534-555.

Dagdeviren, H, Donoghue, M. and Meier, L., (2016) 'The narratives of hardship: the new and the old poor in the aftermath of the 2008 crisis in Europe', The Sociological Review, 65 (2), pp. 369-85

Deeming, C. (2013) 'Addressing the social determinants of subjective well-being: The latest challenge for social policy,' Journal of Social Policy, 42, pp. 541-565.

Desai, M. (2013) 'Social Policy Approaches, Human Rights, and Social Development in Asia,' Social Development Issues, 35, pp. 1-17.

Hick, R. (2012) 'The capability approach: insights for a new poverty focus,' Journal of Social Policy, 41, pp. 291-308.

Kanbur, R (2016) Capability opportunity outcome - and equality, Dyson School, Cornell University, WP 2016-05

Künzel, S. (2012) 'The local dimension of active inclusion policy.' Journal of European Social Policy, 22(1), pp. 3-16. 
Lewis J and Giullari S, (2005) 'The adult worker model family, gender equality and care: the search for new policy principles and the possibilities of a capabilities approach,' Economy and Society, 34, pp. 76-104

Lin $\mathrm{K}, \mathrm{Xu} \mathrm{Y}$, Huang T and Zhang J, (2013) 'Social exclusion and its causes in East Asian societies', Social Indicators Research, 112, pp. 641-660

Marshall, T. H., (1950) Citizenship and Social Class and Other Essays, Cambridge, Cambridge University Press

Maison C, Spinks A, Hajkowicz S, and Hobman L, (2014) 'Exploring the contribution of frontline welfare service delivery to capability development in Australia', Journal of Social Policy, 43, 3, pp. 635-653

McLennan, D., Barnes, H., Noble, M., Davies, J. and Garratt, E. (2011) 'The English Indices of Deprivation 2010,' London: Department for Communities and Local Government

Neckerman, K.M., Garfinkel, I., Teitler, J.O., Waldfogel, J. and Wimer, C., (2016) 'Beyond income poverty: Measuring disadvantage in terms of material hardship and health.' Academic Pediatrics, 16 (3), pp. S52-S59.

Nolan, B. and Whelan, C.T., (2010) 'Using non-monetary deprivation indicators to analyze poverty and social exclusion: Lessons from Europe?' Journal of Policy Analysis and Management, 29 (2), pp. 305-325.

Office of National Statistics, (2012) Consultation on proposed domains and measures of national well-being: responses received. ONS, Newport, Wales

Qizibash, M and Clark, D. A. (2005) 'The capability approach and fuzzy poverty measures', Social Indicators Research, 74 (1), pp. 103-39

Ravallion, M., (2012) 'Mashup Indices of Development'. World Bank Research Observer, 27(1), pp. 1-32.

Ringen S, (1988) 'Direct and indirect measures of poverty,' Journal of Social Policy, 17, pp. $351-65$

Rippin, N., (2016) 'Multidimensional Poverty in Germany: A Capability Approach.' In Forum for Social Economics (Vol. 45, No. 2-3, pp. 230-255). Routledge.

Sen, A. (1985) Commodities and Capabilities, Amsterdam, North-Holland.

Sen, A. (1999) Development as freedom. Oxford University Press.

Shildrick, T. and MacDonald R. (2013) 'Poverty talk: how people experiencing poverty deny their poverty and why they blame the 'poor', The Sociological Review, 61, 285-303

Townsend, P. (1987) ‘Deprivation,’ Journal of Social Policy, 16, pp. 125-146.

Trani, J.F., Bakhshi, P., Noor, A.A., Lopez, D. and Mashkoor, A., 2010. Poverty, vulnerability, and provision of healthcare in Afghanistan. Social Science \& Medicine, 70(11), pp.1745-1755. 
Vizard, P. and Speed, L. (2015) 'Examining Multidimensional Inequality and Deprivation in Britain Using the Capability Approach,' In Forum for Social Economics (No. aheadof-print, pp. 1-31). Routledge.

Wagle, U. R, (2008) 'Multi-dimensional poverty: An alternative measurement approach for the United States?' Social Science Research, 37, pp. 559-80

Whelan, C.T., Nolan, B. and Maitre, B., (2014) 'Multidimensional poverty measurement in Europe: An application of the adjusted headcount approach.' Journal of European Social Policy, 24(2), pp. 183-197.

World Bank (2017) Monitoring Global Poverty, Washington DC 


\section{Appendix}

Table A1: Relationships between metrics of poverty, using lower capability cutoff

(a) Income vs capability poverty

(b) Income vs SWB poverty

\begin{tabular}{ccrr|r} 
& & \multicolumn{3}{c}{ Capability poor } \\
\cline { 3 - 5 } & & \multicolumn{1}{c}{} \\
\hline \multirow{2}{*}{ No } & \multicolumn{1}{c}{ Yes } & \multicolumn{1}{c}{ Total } \\
\hline \multirow{2}{*}{ Nome poor } & No & 48.7 & 30.0 & 78.7 \\
& Yes & 11.1 & 10.2 & 21.3 \\
\hline & Total & 59.8 & 40.2 & 100.0
\end{tabular}

\begin{tabular}{ccrr|r} 
& & \multicolumn{3}{c}{ SWB poor } \\
\cline { 3 - 5 } & & \multicolumn{1}{c}{} \\
\hline Income & No & 63.6 & \multicolumn{1}{c}{ Yes } & Total \\
poor & Yes & 14.1 & 78 \\
\hline & Total & 78.0 & 6.9 & 21. \\
\hline
\end{tabular}

(c) Capability vs SWB poverty

(d) Correlation matrix:

SWB poor

\begin{tabular}{|c|c|c|c|c|c|c|c|c|}
\hline & & No & Yes & Total & & SWB & Capability & Income \\
\hline \multirow{3}{*}{$\begin{array}{c}\text { Capability } \\
\text { poor }\end{array}$} & No & 54.8 & 5.1 & 59.8 & SWB & 1 & & \\
\hline & Yes & 23.3 & 16.9 & 40.2 & Capability & $0.3977^{*}$ & 1 & \\
\hline & Total & 78.0 & 22.0 & 100.0 & Income & $0.1288 *$ & $0.0806^{*}$ & 1 \\
\hline
\end{tabular}

Notes: Panels (a) to (c) are two-way cross-tabulations, in which cells are the proportion of responses in each combination (pooled sample); panel (d) reports correlation coefficients; capability poor metric applies overall cut-off of $0.33(1 / 3)$ - i.e., the individual is considered poor if they are deprived in at least $33 \%$ of all dimensions. 
Table A2: Relationships between metrics of poverty, using higher capability cut-off

(a) Income vs capability poverty

\begin{tabular}{lcrr|r} 
& & \multicolumn{3}{c}{ Capability poor } \\
\cline { 3 - 5 } & & \multicolumn{3}{c}{} \\
\hline \multirow{2}{*}{ No } & \multicolumn{1}{c}{ Yes } & \multicolumn{1}{c}{ Total } \\
\hline \multirow{2}{*}{ Nome poor } & No & 70.7 & 8.0 & 78.7 \\
& Yes & 18.5 & 2.8 & 21.3 \\
\hline & Total & 89.2 & 10.8 & 100.0
\end{tabular}

(c) Capability vs SWB poverty

\begin{tabular}{|c|c|c|c|c|}
\hline & & \multicolumn{3}{|c|}{ SWB poor } \\
\hline & & No & Yes & Total \\
\hline \multirow{3}{*}{$\begin{array}{c}\text { Capability } \\
\text { poor }\end{array}$} & No & 73.4 & 15.8 & 89.2 \\
\hline & Yes & 4.6 & 6.2 & 10.8 \\
\hline & Total & 78.0 & 22.0 & 100.0 \\
\hline
\end{tabular}

(b) Income vs SWB poverty

SWB poor

\begin{tabular}{ccrr|r} 
& & \multicolumn{3}{c}{ SWB poor } \\
\cline { 3 - 5 } & & \multicolumn{1}{c}{} \\
& No & Yes & Total \\
\hline Income & No & 63.6 & 15.1 & 78 \\
poor & Yes & 14.4 & 6.9 & 21. \\
\hline & Total & 78.0 & 22.0 & 100
\end{tabular}

(d) Correlation matrix:

\begin{tabular}{c|ccc} 
& SWB & Capability & Income \\
\hline SWB & 1 & & \\
Capability & $0.2954^{*}$ & 1 & \\
Income & $0.1288^{*}$ & 0.0408 & 1
\end{tabular}

* significant at $5 \%$ level

Notes: Panels (a) to (c) are two-way cross-tabulations, in which cells are the proportion of responses in each combination (pooled sample); panel (d) reports correlation coefficients; capability poor metric applies overall cut-off of $0.66(2 / 3)$ - i.e., the individual is considered poor if they are deprived in at least $66 \%$ of all dimensions. 
Capability indicators

Capability Indicators Used In the OXWELL survey (2011 and 2012)

(Online supplementary materials 2)

(C) Reserved by the copyright holders.

Researchers are free to use or adapt these questions for research but are asked to acknowledge copyright by citing the paper: Anand, P., Jones, S., Donoghue, M., and Teitler, J., (2020) Non-Monetary Poverty and Deprivation: A Capability Approach, Journal of European Social Policy, volume page and DOI to follow

Home related

I am able to share domestic tasks within the household fairly

I am able to socialise with others in the family as I would wish

I am able to make ends meet

I am able to achieve a good work life balance

I am able to enjoy the kinds of personal relationships that I want

I have good opportunities to feel valued and loved

Work related

I am able to find work when I need to

I am able to use my talents and skills at work

I am able to work under a good manager at the moment

I am always treated as an equal (and not discriminated against by people at work)

I have good opportunities for promotion or recognition at work

I have good opportunities to socialise at work

Community related

I have good opportunities to take part in the local social events

I am treated by people where I live as an equal (and not discriminated against)

I am able to practice my religious beliefs (including atheism/agnosticism)

I am able to express my political views when I wish 
Environment related capabilities

I am able to walk in my local neighbourhood safely at night

I am able to visit parks or countryside whenever I want

I am able to work in an environment that has little pollution from cars or other sources

I am able to keep a pet or animal at home with ease if I so wish

I am able to get to places I need without difficulty

Access to services

I am able to make use of banking and personal finance services

I am able to get my rubbish cleared away

I am able to get tradespeople to help fix problems in the house

I am able to be treated by a doctor or nurse

I am able to get help from the police

I am able to get help from a solicitor

I am able to get to a range of shops

Agreement scale: 0 = strongly disagree, $10=$ strongly agree . 